\title{
SMES MARKETING MIX: EXAMINING INFLUENCING FACTORS FOR ITS SUCCESSFUL MANAGEMENT
}

\author{
Juergen Wieland ${ }^{1}$ \\ ${ }^{1}$ University of Gloucestershire, School of Business and Management, Park Campus, The Park, Cheltenham GL50 \\ $2 R H, U K$
}

\begin{abstract}
Purpose - To investigate the influencing factors for the successful management of a standardised marketing mix in the businessto-business (B2B) sector of small and medium-sized enterprises.

Design/Methodology/Approach - A qualitative research through 26 semi-structured in-depth interviews of small and mediumsized enterprises operating in the German business-to-business sector was conducted. The interviewees are involved in marketing mix management decisions and marketing Standardization. Content analysis was used to analyse the collected data.
\end{abstract}

Findings - Results show that no identification of the factors influencing the success of the management of a standardised marketing mix, particularly for the business-to-business sector is available. The study found that a standardised marketing mix is influenced by a number of factors which have to be clearly identified in order to be implemented successfully. This paper identifies and implements these influencing factors for successfully managing a standardised marketing mix.

Research Limitations/Implications - The practical implications of the findings refer to the fact that there does not seem to be a "one and only way" for successfully managing a standardised marketing mix which can be applied to all circumstances and business contexts. Identifying and implementing these influencing factors seems to be a situation specific marketing activity. The significance of the findings notwithstanding, the business-to-business-context of this research, which was conducted with small and medium-sized enterprises, is the most important caveat, as it limits the possibility to generalise its findings to other business contexts.

Practical Implications - This study is important for small and medium-sized enterprises operating in the business-to-business sector which face difficulties in managing their standardised marketing mix successfully. For the successful management of a standardised marketing mix it is vital to get an understanding of its influencing factors. For small and medium-sized enterprises which are attempting to manage a standardised marketing mix effectively an understanding of how to practically implement these influencing factors successfully is important, as it will enable them to develop a marketing mix to overcome price barriers and gain market share.

Originality/Value - This paper provides empirical research on the identification and implementation of influencing factors for successfully managing a standardised marketing mix in the business-to-business sector. The results of the literature review discovered six factors and seven determinants to be implemented within a standardised marketing mix which were not evident in the extant literature.

Keywords - Marketing mix, Standardization, B2B, SME, marketing surveillance

\section{INTRODUCTION}

Managing a standardised marketing mix according to customers' expectations is notoriously difficult for academics and practitioners $[1,2]$. This is particularly true for small and medium-sized enterprises of the business-tobusiness sector, as most of them do not have sufficient experience in managing the factors which influence the marketing mix [1, 3, 4]. A study carried out by Frank, Sommer [5] unveils that many of these small and mediumsized companies face the dilemma that the employees do not have sufficient knowledge about the factors influencing a standardised marketing mix management. An improperly managed marketing mix diminishes a firm's customer base, forces the company to rely on a volatile marketing mix and erodes the firm's market share [6]. Furthermore, inappropriately managed marketing mix factors occur along a continuum of severity [7-10], although the dilemma might be caused by the fact that marketing mix management is not widely accepted in this industrial business-to-business sector [9-11] and that there is no information about the existence of marketing mix management available $[1,5]$.

Studies that have investigated marketing mix management in small and medium-sized enterprises have been discussed in the context of several factors. To gain an understanding of these factors is a vital prerequisite in order to manage them successfully. A body of research examined organizational, 
environmental and stakeholder factors to be implemented within a standardised marketing mix for its successful management [5, 12-17]. Only Teller and Elms [18], Kim and Chintagunta [19] and Stros [20] have examined the effect of mix related factors on the successful management of a standardised marketing mix and argue that no information about their existence is available because they are not yet 'practically implemented'. Other studies investigated the relationship of interdependency factors to successfully manage the Standardization of a marketing mix in an SME context, outlining that, in order to apply it effectively, the marketer has to possess a body of extent knowledge [21-23]. In the same vein, Naik, Raman [24] outline that interdependency factors have be practically implemented, thereby enabling the marketer to "coordinate mix variables in a result-oriented manner". Further research examined relationships between successful interdependencies of price and product mix related factors and their implementation within a standardised marketing mix $[25,26]$, emphasising that they are directly attributable to firms' market success [5].

The studies on influencing factors for successfully managing a marketing mix are valuable, particularly in the light of increasing academic and business attention being given to influencing factors for long-lasting marketing mix success [6]. Hence, if SMEs want to promote long-lasting marketing mix success and reduce poor marketing management decisions, it follows that an understanding of the influencing factors is vital. Furthermore, this study is particularly important for those firms operating in a business-to-business context, because it is important to get an understanding of the factors influencing a standardised marketing mix to overcome price barriers and gain market share. Finally, for those SMEs that manage a standardised marketing mix, the development of recommendations on how to practically implement these influencing factors is highly valuable, as it enables marketers to develop marketing mix management activities more successfully to overcome these price barriers $[5]$.

\subsection{Research in Business-to-Business Enterprises}

Recent studies show that research in marketing mix management in a business-to-business (B2B) context lags a long way behind consumer marketing [27, 28]. Furthermore, most research in a business-to-business context concentrates on marketing services with little focus on the Standardization of marketing mix management $[5,19,29$, 30]. This is supported by Patterson, Johnson [31], concluding that "...there has been an almost total lack of attention to the industrial or B2B sector". Further, research in a business-to-business context could be improved by recognising the "important factors in marketing mix management", as Amirdadjoo, Darvish [32] state, making this a very important area of research [6]. In a B2B context, some papers have been published which examine the factors influencing the success of marketing mix management Standardization [14, 29, 33], such as organizational, macroand micro-environmental and mix related factors and stakeholder factors in a marketing mix context, but no research has been published which investigates the various factors influencing marketing mix management Standardization simultaneously within one single model or approach. Therefore, this research attempts to close this research gap by addressing the following questions:

- What are the influencing factors for the successful management of a standardised marketing mix amongst SMEs in the B2B sector?

- How to can these influencing factors be implemented within a standardised marketing mix in order to achieve their successful management?

For answering these research questions, the paper is structured as follows: First, the literature on Standardization/adaptation and the factors which are vital to managing a standardised marketing mix successfully, particularly in a B2B context of small and medium-sized enterprises, are examined. Subsequently, the methodology is then explained, followed by an analysis of the interviews. Afterwards, the study findings are presented. The paper closes with a discussion of the implications of the research findings and suggestions of avenues for future research.

\section{LITERATURE REVIEW}

\subsection{The Adaptation/standardization Debate}

Research on adaptation/ Standardization of marketing mix management in the business-to-business literature emerged during the 1990s. At the beginning, research findings stressed the fact that existing dissimilarities between SMEs enterprises with respect to culture, economic development, usage patterns, competitive situation and marketing infrastructure call for the adaption of the enterprises' marketing mix to business-to-business market conditions $[34,35]$. Subsequent research [36] has shown that factors favouring the success of marketing mix management (e.g. environmental development, macro- and micro-environment and stakeholders) have to be considered when deciding whether to standardise or adapt a marketing mix. Followed by extensive studies in the subsequent years [37-40], it is now recognised that several factors influence marketing mix Standardization, particularly amongst SMEs operating in B2B markets [41]. As such, these influencing factors have to be integrated to get an optimal marketing mix [42, 43]. Table I summarises the key factors influencing SMEs to follow a standardised or an adapted marketing mix.

\subsection{Adaptation/ Standardization in B2B Markets}

In the same vein, it is a widely accepted fact in B2B literature that the Standardization of the marketing mix can enhance performance when successfully managing its influencing factors and if implemented under specific conditions [44]. Even though small and medium-sized enterprises might achieve greater profitability when adapting their marketing mix according to business-tobusiness market requirements [42], industrial and marketing managers of SMEs often complain the complexity of an adapted marketing mix, particularly with regard to adapting the influencing factors to market specificities [45]. These 
concerns refer principally to the organizational structure of a business (e.g. centralisation of decision-making, allocation of resources, distribution policies), stakeholder factors (consumption patterns and stakeholders' purchasing power) and mix related factors (price Standardization, economies of scale, and company's growth).

Table 1: Factors influencing standardised and adapted marketing mix

\begin{tabular}{|c|c|}
\hline $\begin{array}{lr}\text { Influencing } & \text { factors } \\
\text { favouring } & \text { standardised } \\
\text { marketing mix } & \end{array}$ & $\begin{array}{l}\text { Influencing factors } \\
\text { favouring adapted } \\
\text { marketing mix }\end{array}$ \\
\hline $\begin{array}{l}\text { - The strong linkages } \\
\text { existing in SMEs } \\
\text { between headquarters } \\
\text { and subsidiaries favour } \\
\text { the establishment of } \\
\text { standardised policies. In } \\
\text { this context, } \\
\text { organizational factors } \\
\text { such as the } \\
\text { centralisation for } \\
\text { decision-making for } \\
\text { allocating resources and } \\
\text { establishing policies, } \\
\text { standardised found in } \\
\text { particularly found } \\
\text { SMEs, favour } \\
\text { Standardization. } \\
\text { High similarity in } \\
\text { stakeholder factors and } \\
\text { consumption patterns } \\
\text { amongst SMEs in a B2B } \\
\text { market facilitates } \\
\text { Standardization. } \\
\text { Analogous macro- and } \\
\text { micro-environmental } \\
\text { factors such as } \\
\text { economic growth and } \\
\text { innovation level clearly } \\
\text { favour Standardization. } \\
\text { PME enterprises focus } \\
\text { Price mix related factors } \\
\text { such as a company's } \\
\text { growth and economies } \\
\text { of scale, foremost found } \\
\text { in production of B2B } \\
\text { enterprises, decrease }\end{array}$ & 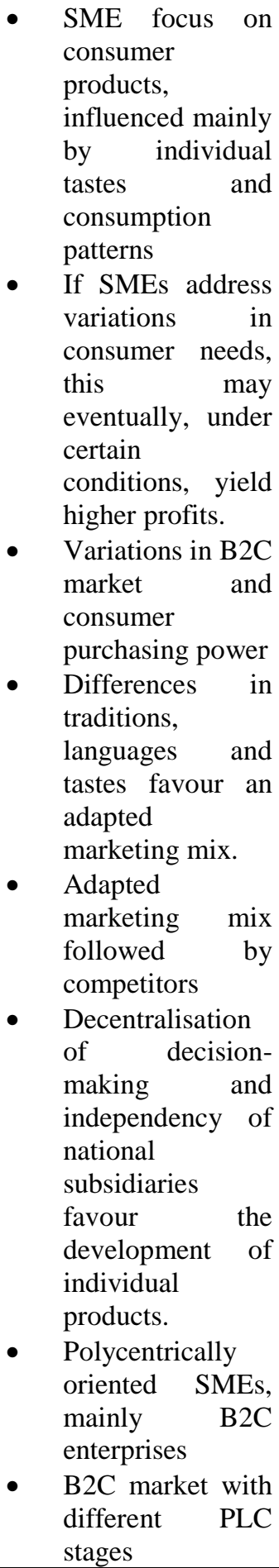 \\
\hline
\end{tabular}

\begin{tabular}{|l|}
\hline costs in R\&D and \\
marketing. \\
Standardised marketing \\
mix with identified \\
interdependency factors \\
followed by competitors \\
An adapted marketing \\
mix leads to high costs. \\
On the highly price \\
driven B2B market the \\
use of standardised \\
marketing mix related \\
factors is more \\
favourable, particularly \\
in the case of SMEs
\end{tabular}

Rodon, Ramis-Pujol [38] conclude that B2B stakeholders tend to be more product driven, as they have an everincreasing desire for quality and service. This is expanded by Davis, Golicic [46], outlining that B2B stakeholders tend to be more price driven compared to $\mathrm{B} 2 \mathrm{C}$ stakeholders. Therefore, by the use of an adapted marketing mix, industrial sellers might achieve higher stakeholder satisfaction and achieve greater profitability (Theodosiou and Leonidou, 2003), but in terms of SMEs of the B2B sector, "significant paybacks are associated with Standardization" [6]. SMEs clearly prefer a standardised marketing mix, because due to economics of scale they are enabled to decrease the price while increasing quality and service [47]. Furthermore, marketing mix Standardization clearly improves export performance, particularly on B2B markets and when SMEs can take advantage of currency exchange rates between countries [48, 49].

\subsection{Factors Influencing Marketing Mix}

\section{Standardization}

Since a standardised marketing mix is influenced by several factors $[10,41,42]$, it is recognised that, particularly amongst SMEs operating in B2B markets, its success is associated with the appropriate management of these factors (Table 1). In the same line with the most recent stream of research, this paper agrees that, when operationalising this concept, for SMEs of the B2B market it is vital to manage a standardised marketing mix and its influencing factors successfully. In doing so, the work by Theodosiou and Leonidou [42] is considered to be the most comprehensive review of the operationalisation of a standardised marketing mix conducted to date with regard to marketing mix management [50, 51]. The authors Theodosiou and Leonidou [42] examined in-depth studies with a total of 35 elements influencing a marketing mix. This work is expanded by Wirtz, Brah [6], investigating influencing factors favouring the Standardization in international B2B markets in a SME context. The authors conclude that SMEs are particularly vulnerable in terms of a poor management of the influencing factors of a standardised marketing mix [6]. As SMEs play a crucial role in the economic security of many nations, it becomes even more important in times of limited domestic growth and recession to get an 
understanding of these influencing factors and of how to practically implement these influencing factors within a standardised marketing mix. As most influencing factors are identified in the studies by Theodosiou and Leonidou [42] and Wirtz, Brah [6], these studies were used as a starting point to get an understanding of the influencing factors of a standardised marketing mix. In line with these authors' suggestions to advance the marketing mix topic, it is ensured that the following major influencing factors are addressed. First, this paper pays great attention to the evaluation of organizational and macro-/microenvironmental factors, as it is the marketing mix managers' perception and not an objective assessment of these influencing factors which is relevant to this study. This is confirmed by Samiee and Roth [35], indicating that the evaluation of managers' perception is highly recommendable, as in the case of the B2B market, SMEs tend to pursue a standardised marketing mix. Second, as this paper focuses on industrial products with highly price driven stakeholders, the stakeholder factors and price/product mix related factors are investigated. Several studies confirm that price driven stakeholders are strongly intertwined with standardised price/product mix variables $[1,12,52]$. Finally, the papers embraces the view that interdependency factors strongly influence the success of a standardised marketing mix, as the thorough analysis of interdependency factors "helps to interpret the relationships occurring between marketing mix variables more effectively" [24]. Consequently, interdependency factors and standardised marketing mix factors are investigated in this research.

\subsubsection{Organizational Factors}

One of the most significant factors appears to be the organisation, which has been incorporated as influencing factor for the successful management of a standardised marketing mix within several studies (e.g. Codita [1], Richter [12], Samiee and Roth [35], Ryans, Griffith [53]). Chung [54] writes that mainly the SME's size, international business experience (IBE) and mode of market entry as part of the organizational factors affect the standardised marketing mix [54]. This is confirmed by a study by Yip [55], stating that the SME's size can be measured by the number of employees or total assets and that SMEs are likely to adapt a standardised marketing mix due to their limited financial resources. The choice for a standardised marketing mix is derived from the fact that SMEs doe access high-cost capital and in comparison to large operations (LOs) and they do not benefit as much from economies of scale as SMEs doe [56]. Kanso and Nelson [57] for example examined marketing practices of SMEs and large operations, concluding that SMEs have much more success when using a standardised marketing mix. Chung [54] confirmed this view, discovering that there exists a significant relationship between the small size of a firm and the degree of Standardization of its marketing mix, as SMEs seek Standardization advantages as competing marketers. The author further argues that, even if the company seeks a niche marketer position, the choice for a standardised approach is highly favourable as SMEs thereby receive important quality and service benefits [54]. In this regard, some studies [1, 12] contend that price benefits further increase the decision for a standardised marketing mix. Naik, Raman [24] further state that SMEs have to encourage their marketers to extend their body of knowledge in order to plan organizational factors effectively and thereby successfully manage a standardised marketing mix. Furthermore, the relationship between international business experience and successful management of a standardised mix has been investigated by several authors, without being yet conclusively elucidated (e.g. Codita [1], O'Cass and Julian [56]). In this, one study reports a negative effect of IBE on Standardization, concluding that firms with high IBE develop higher responsiveness to stakeholders' requirements. This is contradicted by empirical evidence (e.g. Samiee and Roth [35], Kanso and Nelson [57], Chung [58], concluding that IBE of SMEs is related to a high degree with a standardised marketing mix, as the organizational structures and processes of SMEs, as compared to those of LOs, allow them to more effectively contest the price driven stakeholders' requirements. This is confirmed by Zou and Cavusgil [59] stating that SMEs marketing processes with regard to B2B markets enhances the ability to implement marketing Standardization strategies. Jain and Han [10] expand this view, outlining that the SME's size and IBE are rather static in nature compared to the mode of market entry as part of the organizational factors. In this, Codita [1] proposes the implementation of the mode of market entry as a fundamental requisite to be managed for "an effective implementation of the Standardization strategy". The author determines that the SME's managers must share a common world view as well as a common view in terms of export, licensing and minority joint ventures [1]. The SME's specific market knowledge is a solid basis for managing a standardised marketing mix. Richter [12] critically concludes that the SME's strategic consensus has to be achieved on key Standardization issues and influencing factors amongst centrally managed parentmanagers. As in SMEs the authority for setting policies and allocating resources is much more centralised, the initial market entry is much easier when using a standardised marketing mix. As a result, organizational factors act as a main determinant of successful marketing mix Standardization in the SME's B2B setting [60].

\subsubsection{Stakeholder Factors}

Stakeholder factors are conceptualised as factors pertaining to a person or group with an interest or demand in having an endeavour succeed and, in some circumstances, "without whose support the endeavour or demand would fail" [61]. These stakeholder interests or demands require a profound analysis, as this enables SMEs to satisfy the specific expectations by means of a standardised marketing mix, enabling the firm to generate profits [62]. Stakeholder factors not only include the demand to be satisfied, but also the value of the product, based on the perception of what is received and what is given [63], as this enables the establishment of long-lasting relationships, particularly with regard to SMEs $[64,65]$. The literature also discusses stakeholder factors in the industrial production sector, delineating a two-part in the B2B theory. Woodall [66] 
argues that stakeholder factors are intrinsically difficult to evaluate, as stakeholder value is a personal perception of advantage arising out of a stakeholder's association with an organisation's offering and can occur as reduction in sacrifice; presence of benefit. The author suggests that for SMEs the Standardization of stakeholder factors tends to be easier than for LOs, as they design and standardise exceptional products according to B2B needs [66]. The literature in the area of industrial marketing and B2B marketing also suggests that stakeholder factors for industrial goods tend to be more effectively standardisable than for consumer goods [46]. This can be explained by the fact that the marketing mix Standardization is expected to involve a limited subset of stakeholder factors in terms of industrial goods (Codita, 2010). Kotler [67] further writes that SMEs are capable to a high degree to fulfil stakeholders' expectations and reap stakeholders' satisfaction, as these firms go far beyond the Standardization of production functionality and product features. This is confirmed by Czinkota and Coskun Samli [68], showing that stakeholders factors have a very high Standardization potential with regard to B2B product offerings of SMEs, despite the fact that stakeholder factors might be prone to variations in some cases. The propensity to manage a standardised mix in terms of stakeholder factors on a B2B level may also be driven by the expected benefits [69].

The use of a standardised marketing mix in terms of stakeholder factors includes benefits such as cost reduction in all areas of the SME, from research and development to logistics and manufacturing of standardised products according to the B2B stakeholders. A study by Schuiling and Kapferer [70] confirms this, adding that by the use of standardised stakeholder factors substantial savings in labelling, packaging and communication can be made. This in turn enables a higher speed to market, particularly for new B2B initiatives [70]. Several studies (e.g. Codita [1], Richter [12], Alashban, Hayes [69]) confirm the positive effects of a standardised marketing mix in terms of stakeholder factors on cost savings, particularly on the price, product, promotion and place and even on sales volume. As positive effects increases when applying a standardised marketing mix corresponding to the B2B market requirements, SMEs also signal higher quality to stakeholders (Codita, 2010). These results are underlined by empirical evidence [71], showing that the SME's use of a standardised marketing mix is associated with higher quality and prestige in the eyes of the stakeholders. In conclusion, Burgess and Steenkamp [71] empirically tested stakeholder factors as main influencing factors for the successful management of a standardised marketing mix in B2B markets.

\subsubsection{Macro- and Micro-Environmental Factors}

The influence of macro- and micro-environmental factors on a standardised marketing mix is confirmed by several studies (e.g. Codita [1], Jain and Han [10], Chung [54], Evans, O'Malley [72], Yaprak, Xu [73]). Evans, O'Malley [72] write that, among the macro- and micro-environmental factors, economic development, innovation level, physical conditions and marketing infrastructure received the greatest attention, as they are assumed to influence the management of a standardised marketing mix in various ways. This is confirmed by a study by Theodosiou and Leonidou [42], stating that the economic growth will not only influence decisions regarding innovation level and hence the marketing activities, but can also influence the marketing mix strategy. Wei Yap and Yazdanifard [74] choose an illustrative example to depict the influence of innovation level on marketing mix Standardization, as for example the configuration of industrial products affects machinery design and hence may require additional marketing mix strategies. In a further study of product innovation strategies, Leonidou, Kaminarides [75] ascertain the huge influence of physical conditions and innovation level (e.g. B2B market conditions, the SME's size and territory, product design, product features, $R \& D$ ) on the management of a standardised marketing mix. The authors found that similar physical conditions within a B2B market lead to higher price and product Standardization [75, 76]. The influence of physical conditions with regard to marketing mix Standardization has been measured in a study by Cloninger and Swaidan [77], considering similarities within the B2B market as a macro-environmental factor of marketing mix Standardization. Moreover, the influence of macro- and micro-environmental factors on the successful management of a standardised marketing mix is shown by the fact that it impacts a firm's marketing infrastructure which is needed to create, develop and service B2B market demands [78]. A study in B2B markets by Baalbaki and Malhotra [79] found that marketing infrastructure is linked to marketing mix Standardization, proposing that marketing mix Standardization is likely when B2B markets have similar marketing institutions. Katsikeas, Samiee [80] found that, in the case of an inadequate B2B infrastructure, SMEs are forced to modify industrial offerings, pricing and distribution strategy. The authors conclude that empirical findings presumably indicate that macro-/microenvironmental factors have a significant effect on marketing mix Standardization, this being true for almost all strategic marketing mix elements [80]. Codita [1], though, criticises "the scarcity of empirical evidence, particularly with respect to the finer dimensions of this construct, influencing marketing Standardization".

\subsubsection{Price and Product Mix Related Factors}

Price and product are the mix elements considered to have the strongest influences on the successful management of a standardised marketing mix $[1,68]$. In terms of marketing mix Standardization, price and product mix related factors were found to be the most standardisable ones $[1,12,73$, 81]. The interplay between these mix related factors has to be carefully managed in order to be successful with marketing mix Standardization. This applies particularly to pricing, as this mix related factor is the only revenue generating one [68]. Transfer pricing and export pricing are the most important price mix related factors for SMEs operating in B2B markets (Codita, 2010), serving in a standardised manner both as a tool for communication with 
the stakeholder (buyer) and as a competitive tool [82]. Therefore, pricing is considered to have a significant impact on marketing mix Standardization, particularly because SMEs usually use export pricing tools [73]. Henry [81] shows in his study that export pricing tools are highly standardisable and extremely important to the long-term viability of SMEs. Backhaus and Voeth [83] found that both standard worldwide export prices and price Standardization between two B2B markets serve SMEs to create competitive advantage and to attract stakeholders. Studies in B2B markets further indicate that the implementation of price Standardization strategies by the use of sophisticated and systematic policies is indispensable for the SME's success $[82,84]$, as rapid development in communication technology and internet has made prices more transparent to stakeholders [83]. It is indispensable to standardise price decisions due to possible fluctuations in B2B demand, competitive environment and cost structures [79]. Moreover, the factors related to the price mix interact interdependently with product mix elements, explained by the expected economies of scale, rapid entry to new B2B markets, uniform production and uniform quality standards.

Since product mix related factors are considered to have the strongest implications for a successful management of marketing mix Standardization and thereby on a firm's competitive success [82], through the Standardization of product mix related factors, SMEs also will gain competitive advantage in primary and support activities of the value chain [16]. Since product mix related factors form a SME's market offering, they also form the fundament upon which profitable B2B relationships are built (Codita, 2010). Industrial goods are tangible and heterogeneous, SMEs are able to standardise them to a very high degree compared to all other types of goods [67, 85]. As the level of Standardization increases, the quality level increases as well, having the most important implications for marketing mix Standardization [86], starting form pricing issues to positioning aspects to the competition base (Codita, 2010). A number of empirical studies have tested quality level as a main determinant of product mix related factors in SMEs $[69,82,87]$, particularly in the B2B context $[1,88]$. Further, Yip [55] found that a standardised marketing mix does not automatically entail the factors related to a standardised product mix (e.g. product positioning, product features and attributes), due to the availability of distribution channels. In a B2B context, Foxall [89] predicts the SME's stronger Standardization of product mix related factors, due to the emergence of new distribution channels, alliances, expected economies of scale in manufacturing and marketing.

\subsubsection{Interdependency Factors}

In marketing mix Standardization, interdependency factors are described as "relationships in which elements are mutually dependent on each other" [90], to be managed by the SME in an interactive manner in order to pursuit its marketing objectives [56]. Interdependency factors influencing a standardised marketing mix have unique characteristics to be taken into consideration, as "their allocation to several marketing activities referred to as 'planning the marketing mix' is of paramount importance [24]. Thus, interdependency factors are considered to be managed holistically via a tool, rather than as one isolated determinant of marketing mix Standardization [91]. The management of interdependency factors requires a body of extent knowledge [5] contributing to the successful management of marketing mix strategy. Due to significant influences on marketing mix success, the essential components and behaviour of interdependencies have to be analysed, without compromising or restricting the wide range of possible types of relationships [92]. Baker [91] ascribes to the interdependency factors, particularly to essential components such as prioritisation, classification and mapping, the greatest influence on the successful management of marketing mix Standardization. In this situation, the marketer has to possess the necessary knowledge for managing the competitive, harmonic, identical, indifferent and antinomic behaviour of interdependencies adequately in order to standardise the marketing mix successfully [5]. This is supported by a study by Kleinaltenkamp and Saab [88], stating that the successful application of a standardised marketing mix depends to a high degree on the functional form used to model the relationship of interdependencies.

\subsubsection{Marketing Mix Related Factors}

Marketing mix related issues are recognised as a significant factor of any standardised mix management approach $[1,10$, $17,93]$. In the B2B context, it has been suggested that for the successful management of a standardised marketing mix SMEs should take a holistic approach [5]. Furthermore, it is suggested that, depending on the target of the marketing plan, SMEs will take approaches to each of the four Ps in terms of planning, organising and controlling them, taking into account organizational factors [94]. Codita (2010) states that SMEs clearly provide the basis in terms of flexible organizational structures to integrate various influencing factors in the standardised marketing mix. However, some studies are not consistent with this view. Jain and Han [10], for example, show that SMEs are highly integrative in terms of planning, organising and controlling a standardised marketing mix where the influencing factors can be shared amongst different teams within a centralised organisation. Equally, Spence and Hamzaoui Essoussi [15] show that the organisation and controlling of a standardised marketing mix is undertaken by the entrepreneur himself or by a marketing management team. This might be due to the fact that the SME's entrepreneurs normally characterise the organisation structure and marketing planning [15]. Another message found in most studies is that consistency in effective communication and coherence in Standardization is an important marketing mix related factor [16, 95]. It is clearly evidenced that SMEs show an increasing interest in clearly communicating standardised marketing mix related factors, leading to a coherence Standardization of marketing programmes [55]. Effective communication is, therefore, a key marketing mix related factor and relies heavily on the SME's selected Standardization strategy. Furthermore, Kleinaltenkamp, Ehret [96] found in B2B markets that SMEs with a clear communication strategy will be highly 
effective in integrating their mix related factors for successfully managing a standardised marketing mix.

\section{METHODOLOGY}

As the influencing factors for the successful management of a standardised marketing mix of SMEs in a B2B context have not yet been fully explored, a qualitative methodology for this research was chosen. Furthermore, Carson [97] emphasises the fact that qualitative research provides suitability and flexibility for interpreting marketing mix management situations. As a technique, semi-structured indepth interviews were designed, according to the findings of the literature review on the influencing factors of a standardised marketing mix. Several authors confirm that the use of semi-structured in-depth interviews has proven highly successful for the development of a rich view of a variety of Standardization issues [15, 17, 63]. In this context, personal in-depth interviews were expected to be very helpful and prolific in identifying and implementing the influencing factors within a standardised marketing mix for its successful management which have not been addressed in previous research. This research investigated marketers of SMEs operating on a B2B level, who plan standardised marketing programmes and organise and control their influencing factors. This research asks marketers what the influencing factors for successfully managing a standardised marketing mix are [5], then asking labour intention question in the context of how to implement these influencing factors (Codita, 2010). A convenient sample of marketers working for SMEs in a B2B context was selected. Furthermore, measures were taken to ensure the appropriateness of respondents to participate in the study. The sampling of marketers did not have the objective to be representative for any particular industry and therefore, marketers from a wide range of industries participated. The sampling focuses particularly on SMEs within a B2B context. Nevertheless, the sampling was not planned to be representative in terms of a particular geographic region. The marketers participating in this study work for a wide range of industries including mechanics, electrics, process control, pharmaceutics, biochemics, biotechnology and medical controls. The marketing functions exercised by the respondents cover all roles of marketing mix management and marketing Standardization within a sales centre. In total, 26 interviews were carried out with marketers involved in identifying influencing marketing factors and situation analysis. Furthermore, these interviewees carry out, plan, organise and control marketing mix activities and standardise marketing processes. The marketers were involved within the following businesses: mechanical \& electrical engineering, process control, pharmaceutical engineering, biochemical applications, biotechnological manufacturers and medical manufacturers. All of the 26 interviews were conducted in person. The interviewees work for organisations located in Berlin, Munich, and Stuttgart Germany and Basel, Luzern, St. Gallen and Buelach Switzerland. For this research, both small enterprises with not more than 50 employees and medium-sized enterprises with not more than 250 employees were included for ensuring a wide range of expressed insights and opinions.
Scholars suggest to continue sampling until redundancy occurs or saturation is reached in the interviews [98]. Redundancy occurred after about 26 interviews, and a further three interviews were carried out. These additional three interviews represent a safety margin, decreasing the chance to miss important information. In qualitative research projects 26 interviews are seen within the acceptable range of respondents (Carson, 2001). For this research a key informant approach was used, as key informants are seen as employees with particular and unique knowledge and an exclusive position who are capable to empirically report a phenomenon being studied [99]. This approach is widely used in marketing research for receiving answers from one interviewee on behalf of the entire SME [56]. The key informant approach is accepted amongst several authors as a reasonable technique not significantly affecting the results of the marketing study [56, 100]. For ensuring the reliability and unique position of the key informant within the SME, the author selected marketers who had participated in a majority of marketing decision stages. The interviewees admitted that they carry out strategic marketing decisions within the sales centre or within the decision making-unit (DMU) [100, 101]. Authors such as Wirtz, Brah [6] critically conclude that this approach guarantees the respondents' anonymity and impedes the disclosure of any names of the decision making-unit. This is confirmed by Easy [102] and Heide and Weiss [99], emphasising that in qualitative research the key informant approach ensures and encourages profound and candid responses. Given the sensitive nature of this research, this is an important consideration to be made [6]. The interviews began with a brief explanation of the study - for ensuring the respondents' understanding of the factors that influence the successful management of a standardised marketing mix.

In the same line, the respondents were asked to select a marketing mix which they had standardised and answer all questions in terms of the factors influencing this marketing mix. In more detail, they were asked about organizational, macro- and micro-environmental, stakeholder, price and product mix related, interdependency, and marketing mix related factors influencing the standardised marketing mix. The participants were also asked for their opinion on how to plan, organise and control these influencing factors for a standardised mix and on how to implement the essential factors and behavioural interdependencies without compromising the wide range of interdependencies. Only the results from the questions concerning influencing factors asked during the interview are presented in this study. At the end of the interview, the respondents were shortly debriefed, as this establishes credibility when collecting sensitive data [98]. The interviewees were asked questions with regard to a standardised marketing mix they had mixed within the last six month, as the recency bias theory emphasises the fact that respondents recall events having occurred within the last six months more easily [103]. The duration of the interview varied between 60 to 85 minutes. The semistructured in-depth interviews were audio taped in order to enable smoothness of the interview and to capture the respondents' comments more precisely. All interviews were transcribed verbatim. 


\section{DATA ANALYSIS}

For the data analysis and organisation of the multitude of "pages of raw observational notes into a meaningful pattern" [104], template analysis was used. This approach enables the examination of thematically organised open-ended data "to be standardised for the purpose of diagnostics" [105] by the use of coding schemes. Based on the literature review on factors influencing the successful management of a standardised marketing mix, the examination was started. The transcripts were read to develop an intimate knowledge of the data and marked at their margins with different colours. Based on the identification of the specific segments, a preliminary coding scheme was developed. This initial coding scheme then was applied to all transcripts, helping to keep an eye on the segments of highest relevance with regard to the research questions. After familiarisation with the data, the respondents' words were investigated in more detail. After several readings of the transcripts, additional issues in terms of the influencing factors emerged and the initial coding scheme was modified accordingly. All transcripts were re-read, following this modified coding scheme. Furthermore, eyeballing technique, also referred to as ocular scan method, was used to identify the key phrases [106] with the key ideas, thoughts and insights.

\section{RESULTS}

The results from the interviews reveal that getting an understanding of the influencing factors for successfully managing a standardised marketing mix is crucial for the SME's economic success and growth and its ability to overcome price barriers. The reasons for the significance of getting an understanding of these influencing factors included the following: increasing price competition, less failure in price and product portfolio, higher flexibility in negotiation of price conditions, higher degree of commitment, adequate price strategy Standardization, organised management of contract conditions, easier training of marketing personnel, match in product Standardization, standardising organizational factors and culture, increasing consistency in product offerings, communication of product features and attributes to stakeholders, understanding of stakeholders' expectations, meeting stakeholders' demands, accountable person for arrangement of product assortment. In all cases the marketers emphasised the fact that pursuing a standardised marketing mix when operating in a B2B market is recommendable, because the complexity of the marketing mix is reduced. In the same line, the respondents mentioned that by reducing marketing mix complexity, the stages of planning, organising and controlling can be realised much smoother. Further, the respondents mentioned that a standardised marketing mix strategy guides coherence of marketing actions through time. The evaluation of the influencing factors pertaining to the successful management of a standardised marketing mix matched with the six categories previously identified during the literature review. The factors were found to be, in order of decreasing influence on a standardised mix, as follows: organizational factors, stakeholder factors, interdependency factors, price and product mix related factors, macro- and microenvironmental factors and marketing mix related factors.

\subsection{Organizational Factors}

The marketers mentioned that the firm's size, mode of market entry and international business experience are the most important dimensions in terms of the organizational factors. Six respondents gathered factual information about the management's B2B orientation and marketing structure/processes. Four of the respondents related the management's B2B orientation to the willingness to take risks and deal with unfamiliar circumstances, and increase communication with other subsidiaries. These four respondents further mentioned that a centralised organizational structure increases the chance to standardise relationships with subsidiaries, particularly when gathering factual information and analysing organizational structures. One respondent mentioned that, because of corporate restructuring, a Standardization of organizational factors was complicated, resulting in uncertainty of marketing decisions. One of the respondents who did not add further dimensions to the organizational factors, four mentioned that they measured the firm's size by its sales volume and number of employees. They further added that the centralisation of decision-making enables them to benefit from economies of scale and access to low-cost capital and that SMEs seek advantages through Standardization, particularly in B2B markets. Another four respondents stated that the market entry mode is expressed through the B2B market commitment and is driven by the accumulation of market experience and market knowledge. Other respondents commented that as niche market players they seek advantages through marketing mix Standardization, resulting in higher quality of product attributes and features. Others perceived that they avoid structural redundancies through coordination structures such as central account managers and central product managers. They further stated that the Standardization of organizational factors is mainly enabled by embedding stakeholders' requirements in the early phase of the product development process. For example, one responded commented:

I avoid structural redundancies within the company through Standardization. All of the organisation related decisions are made by the headquarter and I try to operationalise the standardised business processes.

\subsection{Stakeholder Factors}

The respondents mentioned that a clear definition of stakeholders' expectations, clear definition of stakeholders' value and satisfaction, the need to train personnel to clearly identify and define stakeholders' expectations, the need to learn about the integration of stakeholders' factors within a standardised marketing mix, investments in product technology to satisfy stakeholders' expectations, initial incrimination in resource consumption to start new stakeholder relations, the need to establish long-lasting B2B relationships, the need to produce exceptional machineries according to B2B needs, the need to provide high quality and service and functional design, and being concerned 
about the bad coordination of PLC-stages would have an impact on stakeholders factors. With respect stakeholders' factors, one respondent mentioned:

You have to clearly identify and define stakeholders' expectations and re-evaluate them after a certain period of time... and the company certainly benefits from the use of a standardised way to integrate the analysed stakeholders' factors within the marketing mix... So, you have to focus on homogenous B2B markets with homogenous stakeholders' requirements... further, the company has to produce high quality machinery to be competitive on the market, if not, you have to compete against low-cost producers even harder.

Other respondents mentioned that their business processes have been changed recently from adapted ones to standardised ones. Management processes, equally, have to be operationalised in a standardised manner to be considerably convenient for the company. They further mentioned that this includes the analysis of stakeholders when gathering factual information, to learn about new processes and arrangements to integrate these processes within a standardised mix, not leaving stakeholders' factors out of concern; for example, a respondent commented:

To exceed customers' expectations it is important to standardise our management and business process; we have to establish long-lasting customer relationships.... Further, we felt that a standardised business process enables us to satisfy the specific demand of our customers. To establish such standardised processes from the scratch is sometimes a question of resources and wages costs.

One respondent even commented that their SME changed to standardised production processes, as these new investments in production processes and product technology help the company to meet stakeholders' expectations. The respondent further mentioned that the need to produce exceptional machineries according to B2B demands forced the company to apply a standardised price and product mix, being true particularly for these two marketing mix elements.

\subsection{Interdependency Factors}

Another category refers to the management of interdependency factors. One respondent commented:

The marketer is a person who has to manage interdependencies in a synergic manner... so it is vitally important to provide a transparent definition and standardised management of the relationships occurring between your mix elements... separating your important mix elements from the less important ones, that is the first step to manage interdependency factors successfully... then putting together these elements, classify and map them requires an extent knowledge.

Other respondents mentioned that there either occur particularly synergic, harmonic and identical interdependencies or, in some occasions, competitive, indifferent and antinomic interdependencies to be managed in a holistic manner. Two respondents mentioned that their firms use an interdependency approach to integrate the identified mix elements and their behavioural interdependencies within a standardised marketing mix, dealing, on the one hand, with the prioritisation, analysis and selection of mix variables. On the other hand, this approach identifies, classifies and maps the different types of interdependencies. Both respondents mentioned that this approach also enables them to successfully control interdependency factors and perform adjustments. The respondents further mentioned that the stage of integrating the interdependency approach within the standardised marketing mix might be labelled 'result-oriented coordination of behavioural interdependencies'. Three respondents mentioned the comparison of mix elements as a reason to use such an approach supporting them in integrating and managing interdependency factors successfully within a standardised marketing mix. One respondent said that:

From a standardised marketing mix perspective, the management of interdependency factors is sort of a primary consideration.... I as a marketer want to ensure work of continuous good quality, therefore we established a process to find out which types of interdependencies exist and how they correlate... This helps me in conducting the standardised marketing activity properly.

A few respondents mentioned that the marketer has to make the SME provide training for marketers to successfully implement interdependency factors within a standardised marketing mix. They further stated that this training has to help them in analysing these influencing factors without compromising or restricting the wide range of possible interdependencies.

\subsection{Price and Product Mix Related Factors}

About 18 respondents mentioned that price and product mix related factors are considered to have the strongest influence on the successful management of a standardised marketing mix, compared to promotion and distribution. One respondent commented this as follows:

I think you have to understand and manage the price and product mix thoroughly, particularly any pricing decision... Because it is a highly competitive tool... In the end, export pricing, price bundling and penetration pricing are the most important strategies to be standardised...

Another respondent mentioned that also transfer pricing and price skimming are usual pricing strategies applied by SMEs. This respondent further mentioned that, particularly in the B2B world, pricing serves as a communication tool attracting stakeholders and as a competitive tool:

In the B2B market most prices, particularly those of machinery manufacturers are standardised to a very high degree. [...] Particularly when constructing premium machineries, the level of Standardization of pricing activities depends on product [strategy] and business strategy in general... it is certain that the 
higher the competition level and stakeholder requirements, the more advisable the Standardization of price and product...

Another respondent explained this as follows:

It has taken us a while to get marketers within the enterprise to understand that the Standardization level of price and product mix policies has to be high [...] Finally, the market environment and its development is an important price and product related factor that impacts the price Standardization a lot. Also, in a niche market, it is recommendable to drive a Standardization, and many SMEs offer their products in such markets.

Other respondents mentioned that, when strategically specifying price mix related factors and when actively planning these standardised price mix related factors, most attributes of the product mix related factors get standardised automatically. The respondents further commented that the stage of strategically specifying and actively planning price and product mix related factors is introduced in their standardised marketing mix process as the second stage after information gathering and situation analysis. Since the Standardization of price and product mix related factors does not only affect primary activities of the value chain but also support activities, higher quality level and economies of scale are the direct results of these Standardization activities. 18 respondents mentioned industrial goods as the most important product mix related factor for standardising any marketing mix activity. One of those respondents said:

It appears to me every working day that industrial goods are by far the most standardisable products, yelling for Standardization... I have had many issues to deal with, including the Standardization of prices of industrial goods. I think it is proven that when selling industrial products, the correlation between price and product mix related factors, and the Standardization potential, is very high...

A few respondents mentioned that the uniformity of price and product mix plays a central role. One respondent explained this as follows:

Standardization itself can be realised by different strategies... as for example denominator and premium strategy... for driving a premium strategy you need a thorough understanding of the market, not forgetting a deep knowledge of distribution channels, as this enables Standardization... also thereby, linkages between price and product determinants [...] are so close, I think all other mixes play a negligible role.

\subsection{Macro- and Micro-Environmental Factors}

Another category to be realised when gathering factual information about the B2B market are macro- and microenvironmental factors. Out of the 26 respondents, 22 of them assumed that in particular physical conditions, economic development and marketing development are the most important determinants of this category, influencing the innovation level of marketing mix Standardization. One respondent provided an example for depicting the influence of these determinants on the successful management of a standardised marketing mix:

I have to investigate the market, examine physical conditions and the general marketing infrastructure... I think it is necessary to acknowledge that the marketing mix Standardization is affected by these kinds of activities... increase of expenditures in R\&D activities positively influences innovation level and machinery attributes... this in turn influences your marketing set and infrastructure...

The remaining four respondents mentioned that the enterprise established a separate marketing strategy for implementing the influencing macro- and microenvironmental factors for the successful management of a standardised marketing mix. They stated that, for the implementation of political-legal and economic factors, the SME provided an integrated concept, whereas this concept is aligned with the overall business strategy. They added that during marketing mix planning and organisation, all developed marketing mix objectives have to be clearly communicated to all involved parties. One respondent extended this by the following statement:

The enterprise has to provide a limited and clearly reduced concept with a clearly functional purpose... The issue is that during marketing mix planning, you have to implement the analysis of the macro- and micro-environmental factors... This is the basis on which an intuitive organisation founds its marketing mix Standardization activities and product portfolio management... Then, you can deduce clear and measurable objectives...

Two respondents complained that they experienced poor integration of macro- and micro-environmental factors. They were concerned about missing a wealthy product portfolio, the integration of clearly measureable objectives and about success within a highly competitive B2B market. These missing linkages force the SME they work for to modify industrial offerings and distribution strategy. One of those two respondents emphasised the importance of acknowledging the problem:

I am sure that it is important to acknowledge the development of a wealthy product portfolio with no more than 4-5 machineries... Therefore, the enterprise has to gather macro- and micro-environmental facts to maximise profit and minimise market overlaps. Particularly when analysing physical features and economic factors, the entrepreneurs of the SME have to be involved...

\subsection{Marketing Mix Related Factors}

25 respondents mentioned that a clearly defined process for planning, organising, controlling and changing a standardised marketing mix is used by one accountable person. 13 respondents further mentioned that in the case of SMEs, it is important to take a holistic approach with the need to clearly identify stakeholders' requirements, the need to profoundly analyse organizational and macro-/microenvironmental factors, the need to train the SME's 
employees in terms of identifying and defining behavioural interdependences, the need to centralise Standardization activities, and take on board the different functions and different levels of persons necessary to realise controlling. On controlling activities, one respondent commented as follows:

We would lose a lot of synergic effects if we did not integrate our controlling activities within the overall business strategy... and I am sure that we certainly would risk the company's well-being, if we did not use a fluid set of guidelines for performance and strategic control... further, the SME would lose its financial control and the company would have to compete much harder against other market-players which understand to set clearly quantifiable objectives.

Another respondent confirmed this view, stating that the SME's marketing and management processes have to be changed, because this change would mean a considerable convenience for the later control and measurement of stakeholder expectations, macro- and micro-environmental and organizational factors. This respondent commented:

We recently established a process to integrate the influencing factors within a standardised approach... Further, we established the necessary sets, procedures and responsibilities from scratch... Thereby we ensure the centralised management of Standardization activities... External specialist and external constituencies are involved, if necessary, within the planning and controlling activities...

Two other respondents mentioned that their companies not only took on board an approach for holistically managing influencing factors within a standardised marketing mix, but that, furthermore, these SMEs introduced company standards on how to identify and define interdependencies. They further mentioned that these company standards result not only in increased convenience for the management of behavioural price and product interdependencies, but that they also serve as a tool to clearly communicate standardised marketing mix related factors; for example, one respondent commented:

We have established a business activity for the management of a standardised marketing mix... This also includes the planning of price and product related interdependencies... But it is sometimes a question of time and of resource costs... So, it helps us to coherently standardise price mix and product offerings...

\subsection{Other Determinants}

The results shown above matched with factors previously mentioned in literature. Moreover, the respondents provided further determinants not yet mentioned in published literature. On the one hand, these determinants have not been mentioned so far and refer very much to general procedures, roles and responsibilities for the implementation of these influencing factors within a standardised marketing mix. On the other hand, the respondents provided these other determinants as general considerations to be taken into account with regard to how to implement these influencing factors within a standardised marketing mix. Therefore, these determinants cannot be classified according to one specific factor and labelled accordingly as determinants. The determinants are:

- Legal issues. A respondent mentioned that his firm contracted an external consultant for planning, organising and controlling the influencing factors within their standardised marketing mix. These SMEs want to protect themselves, as the consultant knows many details about companies' price settings and product portfolio. The SME sees the actual situation with this consultancy as a matter of confidentiality, and therefore seeks for the establishment of particular procedures for managing legal issues with this consultant.

- Risk and change management. Four respondents mentioned that in addition to planning (information gathering and situation analysis), organising (strategy specification/action planning and result-oriented coordination of behavioural interdependencies) and controlling (controlling of measurable marketing objectives) influencing factors of a standardised mix, the minimisation of disruption and errors as a separate determinant has to be taken into account. The respondents mentioned that this determinant helps in implementing operational and strategic changes within a standardised mix and in understanding how unfamiliar circumstances are dealt with and managed. Particularly in marketing mix Standardization, such changes have to be implemented smoothly for ensuring long-term success. The respondents further mentioned that this also includes risk management in the context of standardised marketing mix management, including the identification, assessment, mapping and prioritisation of uncertain circumstances. This thought prompted the respondents to establish a system for mitigating and solving these risks, using available organizational as well as the employees' skills.

- Price and product policy identification. A respondent mentioned that the SME he works for established a separate tool box identifying and defining all price and product elements the marketers are able to use for a standardised marketing mix. The respondent further commented that this includes a description of the various price and product elements of the marketing mix in the context of small and medium-sized B2B enterprises.

- Management's culture and orientation. A respondent mentioned that one of the primary concerns when implementing influencing factors for the successful management of a standardised mix would be entrepreneurs' culture and orientation, which drives the overall business strategy and marketing strategy. The respondent further mentioned that this not only includes the attitude of the entrepreneurs, but also affects the motivation on how to take risks and how to act in unfamiliar circumstances. This thought caused the respondent to establish this determinant as a separate procedure when managing a standardised mix, as he 
perceived that all information regarding the marketing mix needs to be communicated clearly and transparently to all parties involved.

- Centralisation of knowledge. A respondent mentioned that all the existing knowledge on influencing factors for the success of a standardised marketing mix is held by him. The respondent further mentioned that the quality of work is good, and that this is one of the reasons why the SME he works for does not actually invest in knowledge sharing. On the contrary, the company is not interested in knowledge sharing at all, being very successful with contracting one marketer for marketing mix Standardization. According to the respondent, this is a high risk situation, as all knowledge is centralised to the skills of one person; the possibilities to act fast and to fix failures are dramatically reduced when the SME loses staff. This endangers the SME's well-being.

- Impact on other business units. One respondent mentioned that marketing mix planning, organisation and controlling are carried out in cooperation by two business units of the SME he works for. One business unit was not capable to implement influencing factors within a standardised marketing mix successfully, while the other manages these tasks, including the control of measurable objectives, quite successfully. This thought made the SME reluctant to centralise marketing mix Standardization, and, as a consequence, the company was less dependent on one particular business unit, as this business unit held a significant amount of power. The respondent further mentioned that this is realised through a set of corporate policies, including a request for information, being part of a separate procedure to clearly and transparently communicate marketing mix decisions.

- Employees' skills. One respondent mentioned that, with regard to the analysis of organizational, macro- and micro-environmental, and stakeholders' factors, a thorough understanding and application of several techniques (SWOT Analysis, PLC stage, five forces model, Ansoff matrix, PESTLE, and other known tools) is a prerequisite for the successful implementation of these influencing factors within a standardised marketing mix. The respondent further mentioned that for successful marketing mix Standardization it is critical to ensure the employees' skills and knowledge.

\section{DISCUSSION}

The impact of organizational factors was considered to be the major influencing factor within a standardised marketing mix, being raised in 24 personal interviews. These results are discussed below.

\subsection{Organizational Factors}

The results relating to the organizational factors indicate that the impact of the SME's size (measure by sales volume and number of employees), business experience, mode of market entry and centralisation of decision-making are the significant determinants for marketers, impacting on the successful management of a standardised marketing mix. This is in a line with Chung [58], stating that firms are more capable in competing with other SMEs on a B2B market if these determinants are aligned according to a standardised mix and according to a centralised business strategy. This result does not universally imply that on a B2B market, centralisation of decision-making leads to success in marketing mix Standardization. This implies, much more, that business lead and entrepreneurs have to develop a clear concept, particularly with regard to reporting relationships. It has to be noted that the general management of a small and medium-sized enterprise has to undertake an objective analysis of the interconnected linkages between the marketing functions and processes relating to these marketing functions, as the marketer is more likely to plan the marketing mix within the next six to nine months. These results can be explained by the fact that marketers are more likely to seek a Standardization strategy when interconnected marketing functions are clearly communicated and standardised (Codita, 2010). Some of the respondents expand this by stating that the willingness to take risks and act in unfamiliar circumstances increases when the management's B2B orientation and marketing structure/processes are transparent and clear to all parties. This result is contrary to the outcome in B2C markets, where SMEs mostly seek adaptation advantages when unveiling a positive association between marketing structures and processes [57]. In line with the views held by Chung [58] and O'Cass and Julian [56], a standardised marketing structure and the objective communication to all parties seem to explain two aspects: firstly, it recognises that the level of knowledge about standardised marketing structures and processes plays a role in the communication and accumulation of market knowledge and experience; and secondly, it might help to explain why marketers seek a direct mode of market entry when marketing processes are standardised and thereby B2B market knowledge and experience is accumulated. In particular, the Standardization of marketing processes through central account managers and central product managers results in higher product quality and helps firms to act in unfamiliar B2B markets, as market and engineering knowledge is centralised. For this reason, SMEs have to avoid structural redundancies, as this will help them to enter new B2B markets and to proliferate standardised product portfolios according to stakeholders' requirements. Some of the marketers perceived that an early embedding of organizational factors within the product development process enables higher economies of scale and helps in exceeding stakeholder requirements. With an early embedment of organizational factors within a standardised marketing mix, firms become more familiar with the idiosyncrasies of the stakeholders and the B2B market, which causes them to start to standardise more (Codita, 2010). This in turn might be expressed as an enhanced commitment to the B2B market [84]. Consequently, central product managers will gain general skills, engage in active organizational and environmental exploration and 
standardise their marketing mix according to the B2B environment (Richter, 2012).

\subsection{Stakeholder Factors}

The results of this study suggest that SMEs need to train marketers in order to clearly identify and define stakeholders' factors, as a clear identification and definition of stakeholders' factors favours Standardization [107]. Six respondents work for SMEs that clearly identify stakeholders' factors and customers' requirements and thus set clear guidelines or procedures guiding the marketers on how to establish long-lasting B2B relationships. The results show that, on the one hand, this includes measuring stakeholder homogeneity vertically, particularly the similar configuration of the B2B market segments, and looking whether B2B markets are horizontally homogenous for a particular industrial application [52]. Boddewyn and Grosse [62] found that stakeholder factors need a profound horizontal analysis, affecting the Standardization of a marketing mix towards the satisfaction of stakeholders' requirements. High quality, service and functional design of industrial products help exceeding stakeholders' expectations and stimulate competitive advantage on a B2B market. The importance of this aspect was made particularly clear when a respondent commented that a SME certainly benefits from the integration of similar stakeholder requirements and factors within a standardised marketing mix. While Codita (2010) and Chung [54] found the impact of stakeholder similarity to be significant with regard to all facets of marketing mix Standardization, this includes not only the Standardization of the marketing activity itself, but also of the management processes and business processes behind it. Theodosiou and Leonidou conclude in their literature review that empirical findings strongly indicate that stakeholders' factors and the Standardization of the business processes in the background have a significant effect on marketing strategy Standardization. One respondent even claimed that this refers particularly to the Standardization of production processes and production technology, thereby being true specifically for price and product mix Standardization.

\subsection{Interdependency Factors}

Contrary to the literature on the integration of interdependency factors, which states that each unique interdependency has to be managed individually, these factors were considered to be managed in a synergic and holistic manger. A transparent and standardised definition was found to be much more important, separating the less important mix elements form the important ones. A study by Baker [91] confirms this, concluding that interdependency factors have to be managed holistically rather than as one isolated determinant of the marketing mix. However, the obtained results have to be interpreted with caution, since SMEs operating in the B2B sector involve the holistic integration of interdependency factors within a standardised mix [24]. Some of the interdependencies discussed by respondents, particularly synergic, harmonic and identical interdependencies, are assumed to be managed in a standardised way. This includes the application of an interdependency approach, which "helps to interpret the relationships occurring between marketing mix variables more effectively" [24]. Interestingly, while nearly half of the respondents interviewed mentioned that the management of interdependency factors is of paramount importance, only relatively few of them said that they prioritise, analyse, classify and map behavioural interdependencies. This result suggests the promulgation of an extent body of knowledge about the management of interdependency factors, enabling marketers to successfully manage and control these factors [5]. Further research is required to examine the functional form of an approach to model the relationships of interdependencies and to study in which way synergic, harmonic and identical interdependencies impact the successful management of a standardised marketing mix.

\subsection{Price and Product Mix Related Factors}

The results indicate that of the 26 respondents who manage price and product mix related factors, 18 consider product Standardization to have the strongest implication for the successful management of a standardised mix compared to all other elements. These respondents perceive product Standardization as an approach which is characterised by SMEs attempting to exploit B2B opportunities with their industrial products without major adjustments. The respondents mentioned that thoroughly managed price and product elements allow industrial products to be standardised easily according to B2B preferences with very few specific adaptations, realised via offering a standardised set of product attributes and features. The respondents further mentioned that it is crucial to see and manage pricing decisions (particularly transfer pricing, price skimming, export pricing, price bundling and penetration pricing) as a communication tool which is standardised to a high degree according to perceptions of products utility and the offered product attributes. The results show that pricing decisions are a highly competitive tool and an absolutely crucial step in successfully managing a standardised marketing mix. In this context, it is important to not rely on the product strategy alone but to take business and managerial action steps as well. It is also important to understand the seriousness of pricing Standardization decisions of SMEs, being specifically relevant when serving B2B markets of premium products, as they are far less vulnerable to grey imports and smaller fluctuations in local demand. This is confirmed by Richter [12], assuming that a highly standardised price mix is "rather vulnerable to parallel import activities" and seems to be a promising approach, particularly when defining standardised pricing strategies in accordance with a transparent business strategy. A respondent provided an exceptional illustration of this thinking:

Our marketing department acknowledged that pricing Standardization is absolutely crucial, necessarily managed in accordance with the overall business approach and according to the B2B demand... I experienced that in premium segments, products are less vulnerable to parallel imports... It is important to acknowledge that pricing activities depend on a 
thorough analysis of customers' requirements and macro/micro determinants...

24 respondents perceived that failures in pricing decisions not only affect primary activities of the value chain, but also support activities. Results of empirical research indicate that it might be much easier for SMEs to successfully execute marketing mix Standardization when a Standardization strategy, specifically a denominator and premium strategy is applied [1, 68, 92]. These strategies allow a much easier price and product Standardization, due to small fluctuations in local demand, competitive environment, cost structure and taxation. Consistent with marketing mix Standardization theory, decisions of pricing Standardization need to be re-evaluated over time [83]. The integration of pricing decisions within the overall business process is extremely important for the long-term viability of a SME. The findings further indicate that, if price setting decisions are not introduced as a separate step within the overall business approach or market specifications are not handled well, stakeholder satisfaction diminishes and bears consequences for the long-term price and product strategy [68]. Two respondents mentioned that the operationalisation and transformation of the overall business process with regard to the price and product Standardization is influenced by the selling price and profit margins to the trade customer and the sales terms. Conclusively, price and product settings in the B2B world are an overall business task where internal determinants, particularly the SME's goals and objectives, production, marketing cost, and external determinants, particularly stakeholders and competitive characteristics, create strong influences impacting on the successful management of a standardised mix.

\subsection{Macro- and Micro-Environmental Factors}

The results indicate that physical conditions, economic development and marketing development are the main influencing determinants in terms of macro- and microenvironmental factors. These insights cover the results of the literature review and confirm the positive influence of Standardization, as availability and costs of raw materials and labour costs affect the Standardization of "manufacturing activities [...] and marketing strategy decisions such as product design" [76]. A respondent choose an illustrative example to depict the influence of both physical conditions and economic development on the successful management of a standardised marketing mix:

I experienced that machinery design and size... not only affects the selection of machinery components.... as for the premium segment additional features such as very specific micro-filters and flow meters are required, but in a cold location special [...] components are required as well.

Furthermore, a few respondents mentioned that macro- and micro-environmental factors have to be incorporated into an integrative concept within the standardised marketing mix, rather than handling them as a separate factors. A few respondents used PESTLE/STEP analysis as an alternative approach to assess, evaluate, manage, measure and control these factors under the condition that no integrated concept was available. Either way, these insights suggest that the location of B2B markets or groups with similar marketing infrastructure (e.g. Germany, Austria and Switzerland) enables SMEs to apply a standardised marketing mix. This parallels the view by Codita (2010, p. 64), stating that macro- and micro-environmental differences become irrelevant if the company targets homogenous B2B segments. However, the transparent alignment of the overall business approach with these factors is inherently important, as the "Standardization strategy is even more effective when stakeholders are the basis of identifying the segments to serve" [10]. A wealthy product portfolio with clearly quantifiable marketing measures is discussed as a mandatory condition in literature [86].

\subsection{Marketing Mix Related Factors}

The results regarding marketing mix related factors indicate that a predefined holistic approach for planning, organising, controlling and changing a standardised marketing mix is an important factor for its successful management. The results indicate that this not only includes a profound information gathering and situation analysis during the planning stage (analysis of organizational factors, stakeholder requirements, macro- and micro-environmental factors), but also the organisation of price and product elements. These results coincide with those of the literature review and confirm the approach adopted for this study. However, several respondents mentioned that the behavioural interdependencies amongst price and product elements are another important factor, possibly acting as synergic determinant and therefore never to be managed in an isolated manner. Either way, the results further suggest to train marketers effectively and take on board the different functions and levels of persons to realise standardised marketing mix management successfully. The responds see controlling and performance measurement of a standardised marketing mix as an interlinked task, performed via a fluid set of guidelines. The statements further suggest the integration of measureable objectives, communicated clearly to all involved parties and managed by one accountable person.

\subsection{Other Determinants}

The results involving impacts on other business units and legal issues suggest that the success of a standardised marketing mix also may be explained by determinants that, particularly with regard to the long-term viability, are perceived to be a confidential issue. That is, these determinants make marketers reluctant to centralise marketing mix Standardization, including the centralisation of knowledge. Another such determinant includes corporate communication and corporate policy, favouring reciprocal agreements with external stakeholders that result also in transparent communication. However, these reciprocity does not overcome all difficulties regarding communication [67], as internal stakeholders want to overcome centralised knowledge and centralised marketing mix management 
tasks. Therefore, a request for information helps to centralise marketing mix Standardization, making SMEs less dependent on certain business units, maintaining significant amount of power [6]. Similarly, Schuiling and Kapferer [70] in a SME study of the B2B area identify structural bonds to particular business units where particular and unique knowledge in terms of marketing mix Standardization are held. According to Heide and Weiss [99], such structural bonds might be overcome by a centralised management of marketing decisions and by corporate policies, implying a separate procedure to clearly communicate information to all stakeholders involved. This view is expanded by Sandberg [100], outlining knowledge sharing as a central task for successful marketing mix Standardization. Carson [97] states that, therefore, one accountable person should be selected, coordinating the majority of marketing decision stages. Results involving price and product mix related factors suggest that a separate tool box might be implemented, by the means of which price and product mix decisions are successfully managed and measured. As the respondent was particularly involved in price and product decisions, a clear definition of the various price and product elements was paramount. Nevertheless, further research has to be realised to investigate which of the price and product elements play a crucial role for successful marketing mix Standardization. The results involving employees' skills suggest that the thorough understanding of known marketing tools is a critical component to encourage the successful management of a standardised marketing mix. In this, a central notion by Naik, Raman [24] is that marketers' knowledge does not only influence marketing mix management, but also the structure and well-being of the SME. The results involving management's culture and orientation may mean that SMEs have to recognise the significance and value of aligning their management's culture and market orientation with the overall marketing mix Standardization. Kubota [108] suggests that this does not only include the attitude of the SME's entrepreneur, but also a particular procedure with regard to how risk and unfamiliar circumstances are successfully managed. The results involving risk and change management suggest that SMEs have to identify the uncertain circumstances and furthermore have to plan the remainder of the marketing mix process. This determinant also includes the identification and the objectives of stakeholders at the beginning of the marketing mix process. This is confirmed by empirical evidence, suggesting the definition of a framework for the analysis of risk \& change management activities [109]. Some respondents further suggested that risk management includes opportunity management, as modifications are required from the risk management approach implemented within a standardised marketing mix to deal with opportunities effectively. In other words, marketing managers can learn from entrepreneurial mind-sets to deal with uncertain circumstances to adopt and benefit from uncertain changes [110]. Nevertheless, the determinants critically examined above call for further investigation in a broader sense and in a quantitative manner.

\section{MANAGERIAL IMPLICATIONS}

This research brought to light various insights concerning the influencing factors for the successful management of a standardised marketing mix, a subject which until now had received only limited attention by prior research. This research particularly contributes to the existing knowledge of standardised marketing mix management amongst SMEs in the B2B context. This is the reason why this study is highly valuable to marketers for strategic marketing Standardization, specifically for the implementation of factors influencing its successful management as recommended by Frank, Sommer [5]. Since business opportunities in a SME context for understanding the factors underlying the marketing mix Standardization are relatively rare, the greater the knowledge that marketers and specialists have about the factors influencing stakeholders' satisfaction, the higher the ability to plan, organise and control strategic marketing Standardization [21, 24]. It is conceivable that the analysis of organizational, macro- and micro-environmental and stakeholder factors is an ongoing process, and the implementation of a standardised marketing mix within the overall business approach is resource consuming [51, 111]. Nevertheless, an understanding of the different factors influencing a standardised marketing mix allows marketers to direct resources and efforts more appropriately towards its successful management, and enhances long-term business performance resulting from economies of scale and higher stakeholder satisfaction [47]. Marketing managers must align the overall business approach with the marketing mix approach according to the suggestion that Standardization clearly improves export performance [6, 112]. A study by Patterson, Johnson [31] concludes that in this context, "...there has been an almost total lack of attention to the industrial or B2B sector", and therefore, the influencing factors in marketing mix Standardization have to be examined [42]. The results show that in the first stage, during the information gathering and situation analysis stage the organizational, macro- and micro-environmental and stakeholder factors have to be examined [51]; secondly, in the strategy specification and action planning stage the different price and product elements are managed [68]; as a third step follows the result-oriented coordination of the behavioural interdependencies influencing these mix elements [24]. Fourthly, there follows the controlling of measurable marketing objectives (Codita, 2010); and finally, risk \& change management activities are carried out to deal with uncertain circumstances and to reap possible benefits from uncertain changes [110]. The authors Huth and Lohre [109] noted potential problems associated with realising opportunity management, if negative risks and positive opportunities are not strictly separated. Dang (2015) also urges caution when implementing opportunity management, if modifications required by the risk management approach are not strictly separated from opportunity management. The author further explains that risk management does not only simply depend on the organizational factors of the SME, but that, in fact, the macro- and micro-environmental B2B factors in which the SME operates play a key role. Therefore, to benefit from long-term effects of opportunity management, the SME's strategy to exploit competitive 
advantage is based on its thorough analysis of the B2B market, leading to opportunity management strategies rather than to risk management strategies alone to avoid unfamiliar circumstances. On balance, a fluid set of guidelines realised through corporate policy \& communication identified in this research might add value to the successful management of a standardised marketing mix and should therefore be taken into account. Furthermore, this study also has implications for consultant firms serving SMEs, as these firms might include not only internal, but also external stakeholders within their corporate policies and communication, leading to transparent communication and facilitating the establishment of procedures to manage legal issues. The results identify some determinants such as centralisation of decision-making and centralisation of knowledge that make it particularly easy to successfully manage a standardised marketing mix, if the marketing strategy is driven by the overall business strategy.

\section{LIMITATIONS AND FUTURE RESEARCH}

In presenting the findings of this research, it is important to acknowledge its limitations. The sample size, which is appropriate for qualitative research, might be considered only adequate for exploratory investigation and therefore should be further validated by quantitative study. Furthermore, the findings presented in this study are all of an exploratory nature, and no matter how careful and thorough the researcher tried to be, "the practices I observed were seen only through my eyes and registered thought the filter of my expectations and previous experience" [113]. The settings chosen for this research were exhaustive and not random. Therefore, the insights provided must be seen as "those of one person, made in a moderately large but not necessarily representative set of compliance contexts" (Cialdini, 1987, p. 9). For providing a representative set, further quantitative work is needed, addressing the question of whether the influencing factors for the successful management of a standardised marketing mix have a main effect or whether these factors act to some extent as a guiding element. Additionally, this study has been carried out in Germany and Switzerland and therefore, further research has to investigate cross-cultural aspects for the generalisation of these findings. Besides, additional research has to be realised to illuminate the additional determinants investigated in this study but not yet identified in the literature. For future research other issues of interest may include the question how large operations might successfully manage the influencing factors for a standardised marketing mix and the impact of risk \& change management on a standardised marketing mix.

\section{CONCLUSION}

This research empirically investigates the influencing factors for the successful management of a standardised marketing mix in the business-to-business (B2B) sector of small and medium-sized enterprises. The results contributed to knowledge in terms of six factors influencing a standardised marketing mix and seven determinants which were not evident in the extant literature. By identifying and defining these influencing factors, SMEs in the B2B sector gain a better understanding of how to implement these influencing factors within a standardised marketing mix for its successful management. By doing so, organisations with poor marketing mix management can reinforce stakeholders' satisfaction, achieve greater profitability by economies of scale and clearly increase product quality.

\section{REFERENCES}

[1] Codita, R., Contingency Factors of Marketing-mix Standardization in Central and Eastern Europe: Exploring the Influence of Product Cultural Specificity and Further Environmental, Product Related and Organizational Contingency Factors in a Sample of German Consumer Goods Companies, 2010.

[2] Perumal, P., Quest for Excellence Through Globalisation. 2006: Sterling Publishers Pvt. Ltd.

[3] Tambunan, T., Development of SME in ASEAN with Reference to Indonesia and Thailand. Chulalongkorn Journal of Economics, 2008. 20(1): p. 53-83.

[4] Martin, G., et al., Branding:: A New Performance Discourse for HR? European Management Journal, 2005. 23(1): p. 76-88.

[5] Frank, K., L. Sommer, and M. Haug, Potentials of a B2C marketing strategy for automotive suppliers. OEM \& Lieferant IAA, 2010. 1(1).

[6] Wirtz, J., et al., Switching barriers in business-tobusiness services: a qualitative study. International Journal of Service Industry Management, 2006. 17(2): p. 158-192.

[7] Doyle, P. and J. Saunders, Market segmentation and positioning in specialized industrial markets. The Journal of Marketing, 1985: p. 24-32.

[8] Varey, R.J., Internal marketing: a review and some interdisciplinary research challenges. International Journal of Service Industry Management, 1995. 6(1): p. 40-63.

[9] Huang, R. and E. Sarigöllü, How brand awareness relates to market outcome, brand equity, and the marketing mix. Journal of Business Research, 2012. 65(1): p. 92-99.

[10] Jain, M. and F. Han, Identifying the essential factors in the marketing mix design (The case of Personal Protective Equipment). 2012.

[11] Dholakia, R.R. and L.A. Acciardo, Branding a state university: doing it right. Journal of Marketing for Higher Education, 2014. 24(1): p. 144-163.

[12] Richter, T., International Marketing Mix Management: Theoretical Framework, Contingency Factors and Empirical Findings from World-markets. 2012: Logos Verlag Berlin GmbH.

[13] Foxall, G., Corporate Innovation (RLE Marketing): Marketing and Strategy. 2014: Routledge.

[14] Goi, C.L., A review of marketing mix: 4Ps or more? International Journal of Marketing Studies, 2009. 1(1): p. p2.

[15] Spence, M. and L. Hamzaoui Essoussi, SME brand building and management: an exploratory study. 
European Journal of Marketing, 2010. 44(7/8): p. 1037-1054.

[16] Paliwoda, S.J., et al., International marketing adaptation versus Standardization of multinational companies. International Marketing Review, 2009. 26(4/5): p. 477-500.

[17] Bahadir, S.C., S.G. Bharadwaj, and R.K. Srivastava, Marketing mix and brand sales in global markets: Examining the contingent role of country-market characteristics. Journal of International Business Studies, 2015.

[18] Teller, C. and J.R. Elms, Urban place marketing and retail agglomeration customers. Journal of Marketing Management, 2012. 28(5-6): p. 546-567.

[19] Kim, M. and P.K. Chintagunta, Investigating brand preferences across social groups and consumption contexts. Quantitative Marketing and Economics, 2012. 10(3): p. 305-333.

[20] Stros, M., The influence of marketing factors and substance characteristics on pharmaceutical sales in a state-controlled prescriptions pharmaceuticals market, 2012, Aston University.

[21] Owusu-Frimpong, N. and A. Martins, Adoption and implementation of internal marketing systems by Ghanaian small-and medium-sized enterprises. Journal of African Business, 2010. 11(1): p. 26-48.

[22] Thrassou, A., et al., A preliminary strategic marketing framework for new product development. Journal of Transnational Management, 2012. 17(1): p. 21-44.

[23] Kaufmann, H., et al., Transcending innovativeness towards strategic reflexivity. Qualitative Market Research: An International Journal, 2012. 15(4): p. 420-437.

[24] Naik, P.A., K. Raman, and R.S. Winer, Planning marketing-mix strategies in the presence of interaction effects. Marketing Science, 2005. 24(1): p. 25-34.

[25] Zarchi, M.R., et al., Preparation and Designing a Checklist for Health Care Marketing Mix, with Medical Tourism Approach. International Journal of Travel Medicine and Global Health, 2014. 1(3): p. 103-108.

[26] Moiserscu, O. and H. Nguyě, An Exploratory Research for Establishing a Brand Due Diligence Checklist in Mergers and Acquisitions. Romanian Journal of Marketing, 2011. 6(2).

[27] Wegmann, A., et al. Business and it alignment with seam for enterprise architecture. in Enterprise Distributed Object Computing Conference, 2007. EDOC 2007. 11th IEEE International. 2007. IEEE.

[28] Wu, S.-L., Factors influencing environmental strategies among food service franchisors in Taiwan. 2008.

[29] Constantinides, E., The marketing mix revisited: towards the 21st century marketing. Journal of Marketing Management, 2006. 22(3-4): p. 407-438.

[30] Gordon, R., Re-thinking and re-tooling the social marketing mix. Australasian Marketing Journal, 2011. 2(1): p. 127.
[31] Patterson, P.G., L.W. Johnson, and R.A. Spreng, Modeling the determinants of customer satisfaction for business-to-business professional services. Journal of the academy of marketing science, 1996. 25(1): p. 4-17.

[32] Amirdadjoo, N., et al., Effect of market orientation on acceptance of relationship-based pricing in export. Epistemologia, 2015. 12(01): p. 147-159.

[33] Eid, R. and M. Trueman, The Internet: New international marketing issues. Management Research News, 2002. 25(12): p. 54-67.

[34] Fomin, V. and T. Keil. Standardization: bridging the gap between economic and social theory. in Proceedings of the twenty first international conference on Information systems. 2000. Association for Information Systems.

[35] Samiee, S. and K. Roth, The influence of global marketing standardization on performance. The Journal of Marketing, 1992: p. 1-17.

[36] Hsieh, C.-t. and B. Lin, Impact of standardization on EDI in B2B development. Industrial Management \& Data Systems, 2004. 104(1): p. 68-77.

[37] Tin, T.T. and V. Khoo. B2B Standardized Information Interchange Challenges-A Study on Standardization versus Personalization. in Computer Science and Information Technology-Spring Conference, 2009. IACSITSC'09. International Association of. 2009. IEEE.

[38] Rodon, J., J. Ramis-Pujol, and E. Christiaanse, A process-stakeholder analysis of B2B industry Standardization. Journal of Enterprise Information Management, 2007. 20(1): p. 83-95.

[39] Schuh, A., Global standardization as a success formula for marketing in Central Eastern Europe? Journal of World Business, 2000. 35(2): p. 133-148.

[40] Dimitrova, B. and B. Rosenbloom, Standardization versus adaptation in global markets: is channel strategy different? Journal of Marketing Channels, 2010. 17(2): p. 157-176.

[41] Göthlin, A. and A. Jacobsson, A cross-cultural dilemma of standardization or adaptation: A study of Swedish B2B firms marketing activities in India. 2014.

[42] Theodosiou, M. and L.C. Leonidou, Standardization versus adaptation of international marketing strategy: an integrative assessment of the empirical research. International Business Review, 2003. 12(2): p. 141171.

[43] Vrontis, D. and A. Thrassou, Adaptation vs. Standardization in international marketing-the country-of-origin effect. Innovative Marketing, 2007. 3(4): p. 7-20.

[44] Lee, C. and D.A. Griffith, The marketing strategyperformance relationship in an export-driven developing economy: A Korean illustration. International Marketing Review, 2004. 21(3): p. 321334.

[45] Aulakh, P.S. and M. Kotabe, An assessment of theoretical and methodological development in 
international marketing. Journal of International Marketing, 1993. 1(2): p. 5-28.

[46] Davis, D.F., S.L. Golicic, and A.J. Marquardt, Branding a B2B service: Does a brand differentiate a logistics service provider? Industrial Marketing Management, 2008. 37(2): p. 218-227.

[47] Murray, A.I., A contingency view of Porter's "generic strategies". Academy of Management Review, 1988. 13(3): p. 390-400.

[48] Nwankwo, S. and T. Gbadamosi, Entrepreneurship marketing: principles and practice of SME marketing. 2010: Routledge.

[49] Lages, L. and D.B. Montgomery, Export performance as an antecedent of export commitment and marketing strategy adaptation: Evidence from small and medium-sized exporters. European Journal of Marketing, 2004. 38(9/10): p. 1186-1214.

[50] Armstrong, C.E. and K. Shimizu, A Review of Approaches to Empirical Research on the ResourceBased View of the Firm $\uparrow$. Journal of management, 2007. 33(6): p. 959-986.

[51] Terpstra, V. and R. Sarathy, International marketing. 1997, Fort Worth: Dryden Press.

[52] Melewar, T.C., S. Turnbull, and G. Balabanis, International advertising strategies of multinational enterprises in the Middle East. International Journal of Advertising, 2000. 19: p. 529-547.

[53] Ryans, J.K., D.A. Griffith, and D.S. White, Standardization/adaptation of international marketing strategy: Necessary conditions for the advancement of knowledge. International Marketing Review, 2003. 20(6): p. 588-603.

[54] Chung, H.F.L., An investigation of crossmarket Standardization strategies: Experiences in the European Union. European Journal of Marketing, 2005. 39(11/12): p. 1345-1371.

[55] Yip, G.S., Patterns and determinants of global marketing. Journal of Marketing Management, 1997. 13(1-3): p. 153-164.

[56] O'Cass, A. and C. Julian, Examining firm and environmental influences on export marketing mix strategy and export performance of Australian exporters. European journal of marketing, 2003. 37(3/4): p. 366-384.

[57] Kanso, A.M. and R.A. Nelson, Older and bigger: Do larger, more established international firms use standardized advertising more than their younger, smaller counterparts? Journal of Marketing Communications, 2006. 12(3): p. 147-164.

[58] Chung, H.F.L., International marketing decision governance, Standardization, and performance: a framework in the cross-market scenario. European Journal of Marketing, 2010. 44(11-12): p. 1642-1666.

[59] Zou, S. and S.T. Cavusgil, The GMS: a broad conceptualization of global marketing strategy and its effect on firm performance. Journal of marketing, 2002. 66(4): p. 40-56.

[60] Myers, M.B., S. Tamer Cavusgil, and A. Diamantopoulos, Antecedents and actions of export pricing strategy: a conceptual framework and research propositions. European Journal of Marketing, 2002. 36(1/2): p. 159-188.

[61] Nickols, F.W., Why a stakeholder approach to evaluate training. Advances in Developing Human Resources, 2005. 7(1): p. 83.

[62] Boddewyn, J. and R. Grosse, American marketing in the European Union standardization uneven progress. European Journal of Marketing, 1995. 29(12): p. 23.

[63] Parasuraman, A., V.A. Zeithaml, and L.L. Berry, Alternative scales for measuring service quality: a comparative assessment based on psychometric and diagnostic criteria. Journal of retailing, 1994. 70(3): p. 201-230.

[64] Vignali, C. and B.J. Davies, The marketing mix redefined and mapped: introducing the MIXMAP model. Management Decision, 1994. 32(8): p. 11-16.

[65] Lindman, M.T., Formation of customer bases in SMEs. The Marketing Review, 2004. 4(2): p. 139156.

[66] Woodall, A.M., What price the poor?: William Booth, Karl Marx and the London residuum. 2005: Ashgate Publishing, Ltd.

[67] Kotler, P., Standing room only: strategies for marketing the performing arts. 2006, Boston, Massachusetts: Harvard Business School Press.

[68] Czinkota, M. and A. Coskun Samli, The remarkable performance of international marketing in the second half of the twentieth century. European Business Review, 2007. 19(4): p. 316-331.

[69] Alashban, A.A., et al., International Brand-Name Standardization/Adaptation: Antecedents and Consequences. Journal of International Marketing, 2002. 10(3): p. 22-48.

[70] Schuiling, I. and J.-N. Kapferer, Executive insights: Real differences between local and international brands: Strategic implications for international marketers. Journal of International Marketing, 2004. 12(4): p. 97-112.

[71] Burgess, S.M. and J.-B.E.M. Steenkamp, Marketing renaissance: How research in emerging markets advances marketing science and practice. International journal of research in marketing., 2006. 23(4): p. 337.

[72] Evans, M., L. O'Malley, and M. Patterson, Exploring direct and relationship marketing. 2004, Australia; United States: Thomson.

[73] Yaprak, A., S. Xu, and S.T. Cavusgil, The standardization construct in international marketing: earlier conceptualization and suggestions for further development. Handbook of Research in International Marketing, 2012: p. 190.

[74] Yap, S.P.W. and R. Yazdanifard, Comparison on the Impact of Standardization and Adaptation on International Marketing. Journal of Research in Marketing, 2014. 3(1): p. 250-259.

[75] Leonidou, L.C., J.S. Kaminarides, and J.S. Kaminarides, The international marketing environment: Textbook content versus educators' views. Journal of Teaching in International Business, 2007. 18(2-3): p. 101-131. 
[76] Douglas, S.P. and Y. Wind, The myth of globalization. Columbia Journal of World Business, 1987. 22(4): p. 19-29.

[77] Cloninger, P. and Z. Swaidan, Standardization, customization and revenue from foreign markets. Journal of Global Marketing, 2007. 20(2-3): p. 2-3.

[78] Harris, P. and F. McDonald, European business and marketing. 2004: Sage.

[79] Baalbaki, I.B. and N.K. Malhotra, Standardization versus customization in international marketing: an investigation using bridging conjoint analysis. Journal of the Academy of Marketing Science, 1995. 23(3): p. 182-194.

[80] Katsikeas, C.S., S. Samiee, and M. Theodosiou, Strategy fit and performance consequences of international marketing standardization. Strategic management journal, 2006. 27(9): p. 867-890.

[81] Henry, F.L.C., Structure of marketing decision making and international marketing Standardization strategies. European Journal of Marketing, 2009. 43(5/6): p. 794-825.

[82] Czinkota, M. and I. Ronkainen, International marketing. 2012: Cengage Learning.

[83] Backhaus, K. and M. Voeth, Industriegütermarketing, in Innovatives Marketing. 2005, Springer. p. 501-522.

[84] Cavusgil, S.T., Knowledge development in international marketing. Journal of International Marketing, 1998: p. 103-112.

[85] Eggert, A. and W. Ulaga, Customer perceived value: a substitute for satisfaction in business markets? Journal of Business \& industrial marketing, 2002. 17(2/3): p. 107-118.

[86] Kotler, P. and G. Armstrong, Principles of marketing. 2010: Pearson Education.

[87] Shaw, E.H., Marketing strategy: from the origin of the concept to the development of a conceptual framework. Journal of Historical Research in Marketing, 2012. 4(1): p. 30-55.

[88] Kleinaltenkamp, M. and S. Saab, [Technical salesmanagement: an introduction into business-tobusiness marketing] Technischer Vertrieb: eine praxisorientierte Einführung in das Business-toBusiness-Marketing. 2009, Berlin; Heidelberg: Springer Verlag.

[89] Foxall, G.R., Strategic marketing management. 2001, London: Croom Helm.

[90] Powers, T.L. and J.J. Loyka, Adaptation of marketing mix elements in international markets. Journal of global marketing, 2010. 23(1): p. 65-79.

[91] Baker, M.J., The marketing book. 2003, Oxford; Boston: Butterworth-Heinemann.

[92] Becker and P. Egger, Endogenous product versus process innovation and a firms propensity to export. Empirical Economics, 2007.

[93] Lee, A.S. and S. Carter, Global marketing management: changes, challenges and new strategies. 2005, Oxford; New York: Oxford University Press.

[94] AMA. Definition of Marketing. 2007 [cited 2012 09.09]; Available from:
http://www.marketingpower.com/AboutAMA/Pages/ DefinitionofMarketing.aspx.

[95] Calantone, R.J., et al., Internationalization and the dynamics of product adaptation. Journal of Product Innovation Management Journal of Product Innovation Management, 2004. 21(3): p. 185-198.

[96] Kleinaltenkamp, M., et al., For dynamic relationship marketing theory: a reply to Rese. Journal of Business \& Industrial Marketing, 2006. 21(2): p. 9293.

[97] Carson, D., Qualitative marketing research. 2001, London, UK: Sage Publications.

[98] Lincoln, Y.S. and E.G. Guba, Naturalistic inquiry. 1985, Newbury Park: Sage Publications.

[99] Heide, J.B. and A.M. Weiss, Vendor consideration and switching behavior for buyers in high-technology markets. The Journal of Marketing, 1995: p. 30-43.

[100] Sandberg, S., Experiential knowledge antecedents of the SME network node configuration in emerging market business networks. International Business Review, 2014. 23(1): p. 20-29.

[101] Lines*, R., Influence of participation in strategic change: resistance, organizational commitment and change goal achievement. Journal of Change Management, 2004. 4(3): p. 193-215.

[102] Easy, T.M., Key Informant Approach. Methods, 2009.

[103] Crowder, R.G., Short-term memory: Where do we stand? Memory \& Cognition, 1993. 21(2): p. 142145.

[104] Dooley, D., Social research methods. 1990, Englewood: Prentice Hall.

[105] Babbie, E.R., The Practice of social research. 2013, Belmont, CA: Wadsworth Cengage Learning.

[106] Colgate, M.R. and P.J. Danaher, Implementing a customer relationship strategy: The asymmetric impact of poor versus excellent execution. Journal of the Academy of Marketing Science, 2000. 28(3): p. 375-387.

[107] Viswanathan, N.K. and P.R. Dickson, The fundamentals of standardising global marketing strategy. International Marketing Review, 2007. 24(1): p. 46-63.

[108] Kubota, N., How do Japanese manufacturing SMEs facilitate transfer of skills?: Case studies of crosscountry comparison between Japanese and German casting SMEs. Foundry binders and environment, 2011. 5(1).

[109] Huth, M. and D. Lohre, Risk Management in Logistics Enterprises: Results of an Empirical Study. Contributions to Applied International Business Management Research, 2013: p. 26.

[110] Dang, M., From Risk Management to Opportunity Management: An Institutional Approach. 2015.

[111] Terpstra, V., International marketing. 1972, New York: Holt, Rinehart and Winston.

[112] Levitt, T., The globalization of markets. 1985, Boston, Mass.: Graduate School of Business Administration, Harvard University. 
[113] Cialdini, R.B. Compliance principles of compliance professionals: Psychologists of necessity. in Social influence: The ontario symposium. 1987. Lawrence Erlbaum Associates Hillsdale, NJ. 